\title{
Proving the Obvious? What Sensationalism Contributes to the Time Spent on News Video
}

\section{Paul Hendriks Vettehen' and Mariska Kleemans'}

\begin{abstract}
This study investigates the truism that sensationalism in news is a guarantee for success in terms of selling the story to the public. More specifically, it investigates the impact of sensationalist content and packaging features on news viewing behavior. A web-based experiment among 190 participants was conducted in which participants could watch a maximum of 16 news stories that varied in content (neutral vs. negative stories) and packaging (standard vs. tabloid stories). The viewing time per news story was the dependent variable. Results show that sensationalism stimulates viewing time, but also that there are limits to the power of sensationalism. In all, the truism about sensationalism as a guarantee for success appears to be largely true, but not completely.
\end{abstract}

\section{Keywords}

sensationalism, viewing time, negative content, tabloid packaging, news video

The biggest truism about the use of sensationalism in news stories seems to be that it is a guarantee for success in terms of selling the stories to the public. This idea is long-standing: It was already expressed in the early days of the newspaper

\footnotetext{
' Behavioural Science Institute, Radboud University Nijmegen, Nijmegen, the Netherlands

Corresponding Author:

Paul Hendriks Vettehen, Behavioural Science Institute, Radboud University Nijmegen, PO Box 9104, 6500 HE Nijmegen, the Netherlands.

Email: p.hendriksvettehen@maw.ru.nl
} 
(cf. Davis \& McLeod, 2003), and also more recently, it can still be noticed in the many criticisms of news media, for instance, by politicians (e.g., Obama, 2012). Indications for the existence of the truism that sensationalism attracts large audiences can also be found in a number of scientific studies. Studies on sensational TV news have repeatedly shown (although not consistently, cf. Djerf-Pierre, 2000) that competitive pressure emerges as a major factor promoting sensationalism. In particular, these studies found that the more competition exists in news markets, the more sensationalist news stories they provide. In addition, the more news organizations are dependent on advertising revenues (commercial vs. public service stations), the more sensationalist news stories they produce (Arbaoui, De Swert, \& Van der Brug, 2016; Hendriks Vettehen, Beentjes, Nuijten, \& Peeters, 2011; Hendriks Vettehen, Nuijten, \& Beentjes, 2005; Hendriks Vettehen, Zhou, Kleemans, d'Haenens, \& Lin, 2012; Hjarvard, 2000; Hvitfelt, 1994; Slattery, Doremus, \& Marcus, 2001). These findings suggest that increased sensationalist news is generally considered an efficient strategy in the increasing battle for an audience.

A common feature of truisms is that they are rarely tested, probably because the claim being made seems too self-evident. This is also the case for the truism that sensationalism is a guarantee for success. As we will describe in our literature review, indications for the power of sensationalism are widespread, but direct evidence for it is sparse. Therefore, the aim of this study is to test the "sensationalism truism." More specifically, the study focuses on a behavioral measure of news preferences: the time that people spend watching sensationalist news as opposed to nonsensationalist news.

Following most of the literature on sensationalism, the study focuses on news video. In previous research, sensationalism is defined as those content and form features of news stories that are capable of provoking the viewer's senses, in particular of eliciting attention and arousal responses in viewers (cf. Grabe, Zhou, \& Barnett, 2001; Hendriks Vettehen et al., 2005). The literature on sensationalist news video shows some variation in the type of news features identified as "sensationalist," and in the ways in which these features are categorized. This study focuses on two major categories of sensationalist news features that are often discerned. The first category consists of negative topics (e.g., fire, accident, crime, or riots) and the negative pictures (e.g., fire and blood) that usually accompany such stories. We refer to this category as negative content (cf. Lang, Newhagen, \& Reeves, 1996; Soroka \& McAdams, 2015). The second category of news features that are defined as sensationalist is made up of the salient production features that signify sudden changes in content, notably a high number of camera shots but also the presence of sound effects, music onsets, or decorating editing techniques. We refer to this category as tabloid packaging (cf. Grabe, Lang, \& Zhao, 2003; Grabe, Zhou, Lang, \& Bolls, 2000).

\section{Literature Review}

One of the reasons for the common belief in the power of sensationalist news is that there are indications that news consumers have a preference for sensationalist news. 
We review these indications as well as the conceptual and methodological considerations that prevent us from regarding these indications as proof.

\section{Sensationalist News Program Ratings}

In popular discourse, news program ratings or positions of sensationalist versus nonsensationalist news stories in the "most watched" sections of news websites are often used to support the argument that people have a preference for sensationalist news. However, an important limitation of this approach for scientific purposes is that these popularity indicators are likely to be affected by other factors. For instance, the scheduling of news programs can be a methodological confound in comparisons of program ratings (cf. Prior, 2003, p. 152). Likewise, comparisons between viewing statistics of news videos can be affected by the prominence of the news video on the website. Because these factors are not easily controlled for, straightforward comparisons between sensationalist and nonsensationalist outlets in terms of popularity indicators are open to debate when used in scientific studies.

\section{Automatic Responses to Sensationalist News}

A tempting argument in favor of the power of sensationalism might be that sensationalism is by definition attention-grabbing. As we already noted, sensationalism has been defined as those content and form features of news stories that are capable eliciting attention and arousal responses in viewers (Grabe et al., 2001; Hendriks Vettehen et al., 2005). Theoretically, the attention-grabbing value of sensationalist news features has been explained by the assumption that humans are evolutionary predisposed to survey the environment for anything that may be threatening. As a consequence, they will automatically respond to negative information or to sudden changes in the environment. This evolutionary predisposition still remains in modern humans and explains why people automatically respond to negative or salient news features on the screen (cf. Davis \& McLeod, 2003; Lang, 2000; Shoemaker, 1996). In addition, laboratory studies revealed that both the sensationalist categories of negative content and tabloid packaging features had the expected positive effect on physiological indicators of (short term) attention and arousal responses in viewers (e.g., Grabe et al., 2000, 2003; Lang et al., 1996; Soroka \& McAdams, 2015).

Still, although sensationalist news features do have attention-grabbing and arousal eliciting potential, it is important to note that automatic viewer responses to sensational news do not necessarily imply that sensational news will keep viewers glued to the screen. As Kleemans, Hendriks Vettehen, Beentjes, and Eisinga (2012, p. 681) pointed out, short-term attention and arousal responses while watching sensationalist stories are conceptually different from preferences for these stories in terms of more long-term viewing behavior. More in general, human behavior may not only result from automatic processes but also from higher order cognitive processes (e.g., Ajzen 
\& Fishbein, 2000). This also applies to more long-term viewer responses to sensationalism, which are likely to be affected by viewer motivations and expectations.

\section{The Gratifying Potential of Sensationalist News}

Research has shown that people are more likely to watch the news if they can expect to get something out of it. Particularly, two broad categories of instrumental motives to engage with news have emerged from news gratifications studies: motives associated with information gain (surveillance, social uses) and with entertainment (excitation; e.g., Palmgreen, Wenner, \& Rayburn, 1980; Rubin, Perse, \& Powell, 1985). To the extent that sensationalist news features contribute to information gain and provide entertainment, viewers can be expected to actually feel that they "get" something out of the news, and as a consequence, they are likely to have a stronger preference for sensationalist news. Thus, theoretical expectations about people's exposure to sensationalist videos may be based on knowledge regarding the extent to which sensationalist features have shown to be beneficial in informing and entertaining viewers. Both the information providing and entertaining potential of sensationalist news have been studied.

A first line of studies investigated the effects of sensationalist news features on the processing of information in the news. Theoretically, most of these studies were based on a limited capacity model of information processing (Lang, 2000). In a nutshell, this model holds that humans have a limited pool of cognitive resources. The quality of information processing depends on the balance between the amount of processing resources people allocate to the task and the amount of processing resources that are required for the task. Both negative content and tabloid features automatically elicit the allocation of additional cognitive resources to the processing of the messages. As a result, one might expect that memory would be better for negative or tabloid packaged news than for neutral or standard packaged news, and some studies indeed show such an effect (e.g., Grabe et al., 2003; Lang et al., 1996). However, the presence of both negative content and tabloid packaging features also imposes a burden upon the information processing resources that might evoke cognitive overload. In accordance with this idea, research findings show that particularly the combination of negative content and a tabloid style of production has a zero or even negative effect on memory (Grabe et al., 2000, 2003).

The effect of negative content also appears to be conditional upon viewer features, particularly gender. Grabe and Kamhawi (2006) found that men recognized and comprehended negative news better than positive news, whereas the opposite was true for women. In a follow-up study, these authors found a similar pattern on subjective ratings of news stories as informative (Kamhawi \& Grabe, 2008). According to the authors, these findings qualify the idea that humans are evolutionary hardwired for negative news: It might well be that particularly men rather than women are predisposed to approach threatening stimuli in their environment to protect their offspring 
from threats. This predisposition would explain their stronger responses to negative news (Kamhawi \& Grabe, 2008).

A second line of studies investigated enjoyment for sensationalist versus nonsensationalist news. Grabe, Zhou, Lang, and Bolls (2000) found that negative stories that were packaged in a tabloid style were enjoyed less than negative stories that were packaged in a neutral style. This finding is in accordance with findings by Hendriks Vettehen, Nuijten, and Peeters (2008) and Kleemans, Hendriks Vettehen, Eisinga, and Beentjes (2014) that both showed that the arousal that was elicited by sensationalist features was positively related to enjoyment, but only up to a moderate level of arousal. News stories that elicited high levels of arousal (stories that included more arousal eliciting features) were enjoyed less. In the Hendriks Vettehen et al., (2008) and Kleemans et al.,'s (2014) studies, the findings were explained from the general idea of optimal arousal that has been incorporated in a number of theories, for instance, flow theory (Csikszentmihalyi, 1992) and the activation model of information exposure (Donohew, Lorch, \& Palmgreen, 1998). A common assumption in these theories is that humans strive toward an optimal level of arousal, at which they feel most comfortable. Following this idea, moderate amounts of sensationalist features (negative content or tabloid packaging features, not both) in news stories could evoke moderate levels of arousal, which in turn would be enjoyed most. In contrast, very low and very high (negative content and tabloid packaging features) amounts of sensationalist features would be enjoyed least - which is exactly what Grabe et al., (2000), Hendriks Vettehen et al., (2008), and Kleemans et al., (2014) found.

Similar to the findings on the processing of sensationalist news, the enjoyment of sensationalist news also appears to be conditional upon viewer features. Kamhawi and Grabe (2008) found that men enjoyed negative news more than positive news, whereas the opposite was true for women. Kleemans et al., (2014) found that older viewers felt less enjoyment when the sensationalist features elicited higher levels of arousal than younger viewers felt.

Overall, the studies on information processing and enjoyment provide similar findings: Sensationalist features in news stories promote memory and enjoyment. However, large amounts of sensationalist features may be detrimental. Moreover, female and older viewers appear to respond less positively to sensationalism. Based on the premise that most people prefer news that gratifies their needs for information or entertainment, similar findings may be expected for news preferences. Clearly, however, these are still expectations, no proof.

\section{Preferences for Sensationalist News}

Only two studies exist that investigated the impact of both negative content and tabloid packaging on viewer preferences (Bailey, Fox, \& Grabe, 2013; Kleemans et al., 2012). By and large, the findings from these studies square well with those from studies using memory and enjoyment as dependent variables described above. However, two important remarks should be made that justify the current investigation. 
First, both studies were somewhat limited. Kleemans et al., (2012) merely measured viewing intentions (i.e., the likelihood to stay tuned, if being given the opportunity to switch to another channel, and story choice for pairs of news stories). Although undoubtedly both are correlated, viewing intentions do not equate with viewing behavior. The Bailey et al., (2013) study was better designed to study the effects of sensational news features on viewing behavior: It featured a free choice environment, behavioral measures, and a manipulation of both content and formal news features. However, it was conducted on a small-scale, using a homogeneous sample of 50 student participants.

Second, and perhaps even more important, the Bailey et al., (2013) study found a result that seems to be at odds with both theoretical predictions and past findings on related variables. Bailey et al., (2013) found an interaction, indicating that the combination of negative content and tabloid packaging drew longer viewing times than the added effects of negative content and tabloid packaging would suggest. In contrast, the findings from studies on information processing and enjoyment of sensational news would suggest that viewers spend more time on news containing either negative content or tabloid packaging features than on the combination of these, which could induce cognitive overload (Grabe et al., 2000, 2003) or overstimulation (e.g., Grabe et al., 2000; Hendriks Vettehen et al., 2008; Kleemans, Hendriks Vettehen et al., 2014). So, an important aim of this study is to investigate whether using sensationalism to stimulate viewing is a matter of "the more, the better" (as suggested by the Bailey et al.,'s study) or whether there are limits to the power of sensationalism (as suggested by theory and findings on related variables).

\section{Hypotheses and Research Questions}

Recognizing the importance of replication as the keystone of science, the design of the current study is basically similar to the Bailey et al., (2013) study. However, it uses a larger sample. We pose the following hypotheses and research question:

Hypothesis 1: Viewing time is longer for negative content stories than for neutral content stories.

Hypothesis 2: Viewing time is longer for tabloid packaged stories than for standard packaged stories.

Research Question 1: To what extent is viewing time affected by a combination of negative content and tabloid packaging?

Our literature review showed that effects of age and gender were not consistently found, but if they were found, they were coherent regarding the direction of the effect. The larger sample of this study enables us to investigate whether effects of negative content (vs. neutral content) and tabloid packaging (vs. standard packaging) features vary between age and gender categories. In all, we expect that: 
Hypothesis 3: The difference between viewing times of negative content and neutral content will be larger for younger viewers than for older viewers.

Hypothesis 4: The difference between viewing times of tabloid packaged stories and standard packaged stories will be larger for younger viewers than for older viewers.

Hypothesis 5: The difference between viewing times of negative content and neutral content will be larger for men than for women.

Hypothesis 6: The difference between viewing times of tabloid packaged stories and standard packaged stories will be larger for men than for women.

\section{Method}

Design

A web-based experiment was conducted in which participants were instructed to watch 16 audiovisual news stories that were presented on a website. In this experiment, a 2 (content) $\times 2$ (packaging) $\times 2$ (age) $\times 2$ (gender) mixed design was used Age (young vs. old) and gender (male vs. female) were between-subjects factors. Content (neutral vs. negative stories) and packaging (standard vs. tabloid stories) were within-subjects factors.

\section{Stimulus Materials}

The stories that were used as stimuli in the experiment were previously used in other studies regarding the effects sensationalist news (cf. Kleemans et al., 2012, 2014). All stories had been broadcast in the evening news program Het Journaal (the main news program in the country in which the study was conducted, i.e. The Netherlands). Potentially, useful stories were derived from a content analysis (see Hendriks Vettehen et al., 2012 for detailed information). The stories that were included in the experiment had a number of characteristics in common to largely eliminate effects from factors other than differences in content and packaging. For instance, news anchors were replaced by written introductions, stories only contained domestic news, did not report on controversial issues or topics that has received extraordinary media attention, and had little variation in story length $(M=95.31 \mathrm{~s} ; S D=10.78)$.

The selected stories already differed with regard to content and packaging but were in some cases edited to a certain extent to enlarge the differences in production style. For instance, camera shots were added or excluded and decorative editing techniques were included. This resulted in eight stories containing tabloid packaging and eight stories containing standard packaging. Half of the stories of each category had a negative content (e.g., about riots or crime), and the other half included neutral content (e.g., about culture or economics). Regarding the content, a pilot study $(N=51)$ was 
conducted to test whether the stories were indeed distinct. Results showed that the valence of the stories - measured on a scale ranging from 1 (negative) to 7 (positive) - differed in the expected direction between negative $(M=2.85 ; S D=.81)$ and neutral $(M=4.41 ; S D=.95)$ stories. Thus, the 16 stories presented on the website were categorized into four types: each possible combination of the two types of content and the two types of packaging.

\section{Participants}

Snowball sampling was used to recruit participants. A total of 218 Dutch participants took part in the experiment. Of this sample, 190 participants were highly educated (i.e., having completed education at a university, currently studying at a university, or currently attending the highest level of secondary education that prepares for tertiary education at a university). A small minority of the snowball sample (28 participants) had a low level of education. Because of this small subsample, which would not allow for breaking down data in age and gender categories, we decided to exclude these participants. To achieve maximum power, we applied a median split to almost equally divide the 190 participants in two age groups: 99 younger ones (15-25 years; 51 male and 48 female) and 91 older ones (26-55 years; 53 male and 38 female). Participants did not receive a fixed reward for their participation, but to enhance participation, three gift coupons were raffled after the experiment.

\section{Procedure}

Before the start of the experiment, participants were asked to eliminate any potential source of external distraction before proceeding to the experiment, particularly electronic devices. Next, they were exposed to a website that presented screenshots of the 16 news stories in a random order. The instruction was to spend some time watching news stories, with a maximum of $15 \mathrm{~min}$. Within this timeslot, participants could watch as many of the 16 stories as they would like to watch, and they could switch to another news story as often as they would like to switch. Although a time limit was imposed upon participants, they needed considerably less time to watch the stories. On average, they spent $10 \mathrm{~min}$ and $28 \mathrm{~s}$, with a minimum of $4 \mathrm{~min} 29 \mathrm{~s}$ and a maximum of $14 \mathrm{~min}$ and $15 \mathrm{~s}$. So, in practice participants were able to watch as much as they liked.

\section{Variables}

Besides measuring age and gender, the viewing time per news story was recorded online. These records served as a basis for the viewing times in each of the four content by packaging categories. For each category, the mean viewing time of the stories in the category that had been watched for at least a second was calculated. Sixty percent of the participants watched all 16 news stories. Of the $40 \%$ that ceased watching at an earlier moment, each participant had watched at least three of the four 
stories in each category. As a result, the mean of each category was calculated on the basis of at least three (and mostly all four) stories within the category. The mean viewing time, based on all stories that had been watched, was $41.81 \mathrm{~s}(S D=9.81)$. This implies that overall, participants watched most stories to somewhat less than halfway, and that hardly any story was watched until it ended (story length varied between 78 and $112 \mathrm{~s}$ ).

\section{Findings}

A full factorial 2 (content) $\times 2$ (packaging) $\times 2$ (age) $\times 2$ (gender) repeated measures analysis of variance was carried out. The findings that directly bear upon the hypotheses were the following. In support of Hypothesis 1, a main effect for content was found, $F(1,186)=1,158.20 ; p<.001 ; r=.93$. Viewers continued watching negative content twice as long compared to neutral content $(M=55.84, S E=.86$ vs. $M=$ $27.82, S E=.77)$. In support of Hypothesis 2, a main effect for packaging was found, $F(1,186)=14.63 ; p<.001 ; r=.27$, indicating that viewers spent more time watching tabloid packaged stories than standard packaged stories $(M=42.98, S E=.77$ vs. $M=$ $40.68, S E=.76)$. Answering Research Question 1, content and packaging appeared to interact, $F(1,186)=41.12 ; p<.001 ; r=.43$. Participants watched longer to the combination of tabloid packaging and neutral content stories than to the combination of standard packaging and neutral content stories $(M=30.79, S E=.95$ vs. $M=24.85$, $S E=.80 ; p<.001)$. In contrast, they watched tabloid packaged negative stories and standard packaged negative stories equally long $(M=56.51, S E=1.00$ vs. $M=$ 55.16, $S E=.90 ; p=.106)$.

Regarding the moderating role of age and gender, the following results were obtained. In accordance with Hypothesis 3, an interaction between negative content and age was found, $F(1,186)=10.42 ; p=.001 ; r=.23$. Post hoc analyses provided further support to Hypothesis 3 by showing that the difference in viewing times between negative content and neutral content was somewhat larger for younger participants than it was for older participants: Younger participants watched $30.67 \mathrm{~s}$ longer to negative content stories than to neutral content stories $(M=55.67, S E=1.18$ vs. $M$ $=25.00, S E=1.06 ; p<.001)$, whereas older participants watched $25.36 \mathrm{~s}$ longer to negative content stories than to neutral content stories $(M=56.00, S E=1.25$ vs. $M=$ $30.64, S E=1.12 ; p<.001)$. Finally, the analysis of these means also revealed that older participants watched longer to neutral content stories than younger participants $\operatorname{did}(\Delta M=5.65 ; p<.001)$. However, they watched negative content stories equally long $(\Delta M=.33 ; p=.846)$.

The interaction between negative content and gender, although weak and only marginally significant, $F(1,186)=2.87 ; p=.092 ; r=.12$, showed a similar pattern. Post hoc analyses showed that the difference in viewing times between negative content and neutral content was slightly larger for male participants than it was for female participants: Male participants watched $29.41 \mathrm{~s}$ longer to negative content stories than to neutral content stories $(M=54.92, S E=1.15$ vs. $M=25.51, S E=$ 
$1.04 ; p<.001$ ), whereas female participants watched 26.62 longer to negative content stories than to neutral content stories $(M=56.75, S E=1.27$ vs. $M=30.13, S E=$ $1.15 ; p<.001)$. However, this support for Hypothesis 5 is marginal at best, as the significance level of the interaction already showed. Finally, the analysis on these means also revealed that female participants watched significantly longer to neutral content stories than male participants $\operatorname{did}(\Delta M=4.61 ; p=.003)$. However, they watched negative content stories equally long $(\Delta M=1.82 ; p=.289)$.

The expected interactions between tabloid packaging and either age (Hypothesis 4 ) or gender (Hypothesis 6) were not found.

Apart from these findings that directly bear upon on hypotheses and research question, the analysis revealed a number of other findings. First, main effects of both age, $F(1,186)=4.51 ; p=.035$, and gender, $F(1,186)=5.23 ; p=.023$, were found. Overall, older participants watched significantly longer $(M=43.32, S E=1.02)$ than younger participants $(M=40.33, S E=.97)$, and female participants $(M=43.44, S E$ $=1.05)$ watched longer than male participants $(M=40.22, S E=.94)$. Second, a number of unexpected interactions were found including three-way interactions between tabloid packaging, age, and gender, $F(1,186)=5.72 ; p=.018$; negative content, tabloid packaging, and age, $F(1,186)=4.77 ; p=.030$; and a four-way interaction between negative content, tabloid packaging, age, and gender, $F(1,186)=$ $4.70 ; p=.032$. Because the four-way interaction depicts the most qualified view on the data, we analyzed this interaction more in detail.

The four-way interaction shows that the two general patterns in the data that together constituted the interaction between content and packaging do apply for all four categories of participants except one: older female participants. As Figure 1 shows, the pattern that tabloid packaged stories with neutral content drew longer viewing times than standard packaged stories with neutral content was found for all four categories of participants (younger men: $p=.020$; older men: $p<.001$; younger women: $p=.009$; older women: $p<.001$ ). As Figure 1 also shows, the pattern that tabloid packaged stories with negative content did not draw longer viewing times than standard packaged stories with negative content was found for three of the four categories of participants (younger men: $p=.124$; older men: $p=.289$; younger women: $p=.547$ ). Diverging from this pattern, older female participants watched shorter to tabloid packaged negative stories than to standard packaged negative stories $(p=.003)$.

\section{Discussion and Conclusions}

The main conclusion of this study is that the truism about sensationalism as a guarantee for success appears to be largely true. The findings show that sensationalism indeed has the power to boost viewing time and that this is particularly true for the presence of negative content, which has a large effect on the time spent on news video. Overall, the old newsroom saying "if it bleeds, it leads" is confirmed as a wise strategy 


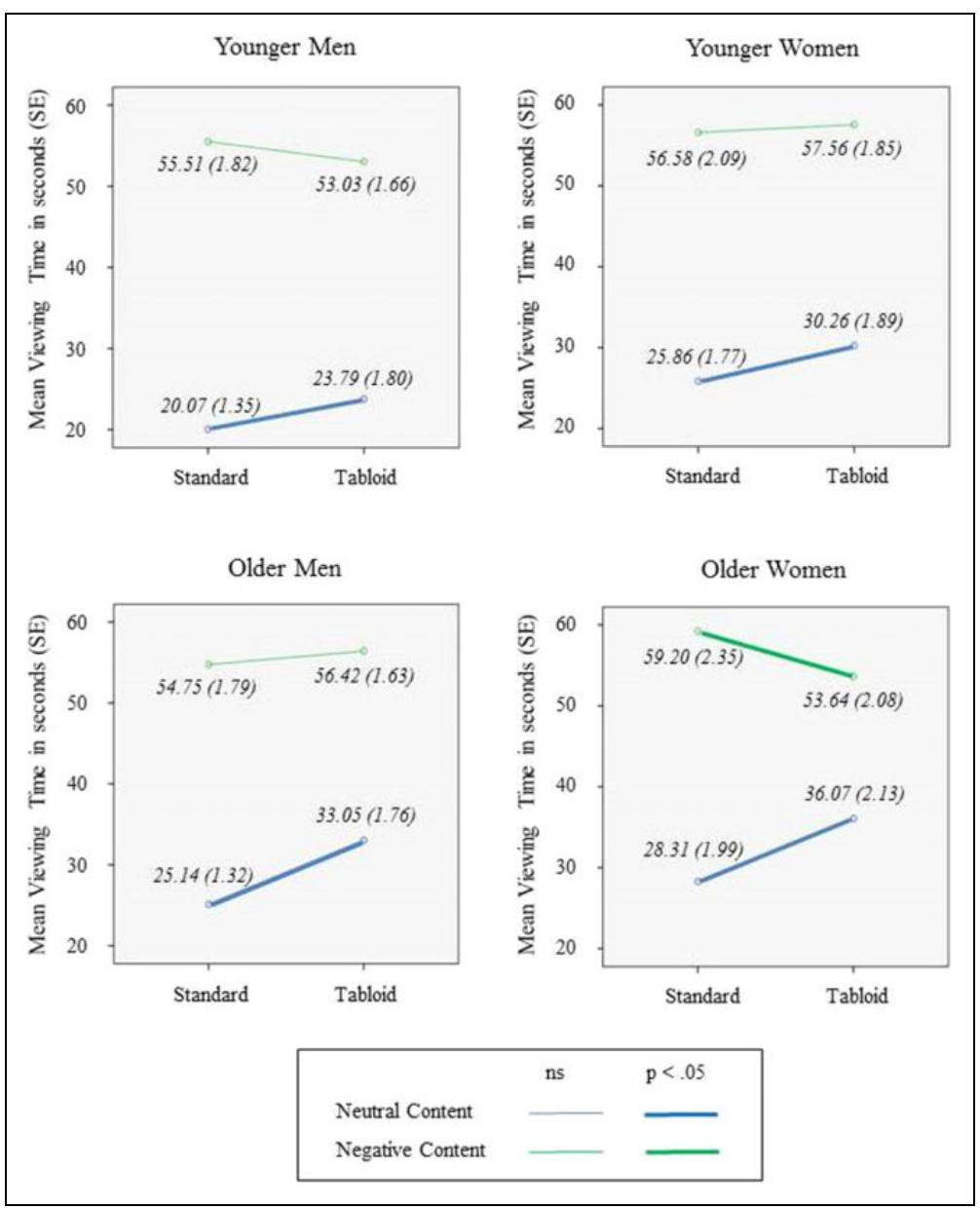

Figure I. Interaction between content, packaging, age, and gender.

for news directors who aim at not merely attracting but also holding viewers' attention.

There are, however, a number of findings that suggest limits to the power of sensationalism. First, although tabloid packaging does promote viewing of content that participants do not spend much time on (neutral content), it does not promote viewing of content that participants already spend much time on (negative content). Second, although negative content promotes the viewing time among younger participants (who only spend little time watching neutral stories), it adds somewhat less to the viewing time of older participants (those who already spend quite some time watching neutral stories). Third, adding tabloid, sensational form to already negative 
content even leads to a decreased viewing time among older women. So even though in general sensationalism is a guarantee for success, news producers need to be cautious.

The main patterns that are found in this study are in accordance with the patterns that emerged from our literature review. Notably, this literature generally shows larger impacts of (negative) content features than form features on physiological responses, news processing, and news preferences (e.g., Bailey et al., 2013; Grabe et al., 2000, 2003; Kleemans et al., 2012), which was what we also found in this study. In addition, the literature shows how large amounts of sensationalist features may induce cognitive overload and overstimulation (Grabe et al., 2000, 2003; Hendriks Vettehen et al., 2008; Kleemans et al., 2014) and that particularly female and older viewers can even experience negative effects of sensationalism (Grabe \& Kamhawi, 2006; Kamhawi \& Grabe, 2008; Kleemans et al., 2014). This result is also reflected in our study findings.

The study also highlights why replication is important. Bailey et al., (2013) reported that the combination of tabloid packaging and negative content drew the longest viewing times, which suggests that the rule "the more, the better" applies when it comes to using sensationalism to stimulate news viewing. Against the background of our literature review, this finding was both theoretically and empirically counterintuitive. One might argue that of all the studies that we reviewed, the Bailey was best designed to study viewing times of more or less sensational news stories. However, it was just one study, using a small student sample. Our study findings did not replicate this counterintuitive finding, it rather showed results that square well with theory and findings on variables like memory and enjoyment.

\section{Limitations}

The major limitations of this study are typical of this type of experimental research. First, the variance in negativity and tabloid features within the stimulus sample was limited by the boundaries of current news reporting. Second, and probably more importantly, the participant sample was limited to highly educated participants. One might question whether less educated participants would show equal responses to sensationalist news stories (cf. Grabe, Yegiyan, \& Kamhawi, 2008). Consequently, even though we related our study findings to other findings in the literature, some caution is required in generalizing them.

\section{Suggestions for Further Research}

To ensure ecological validity of the study, the two sensational categories negative content and tabloid packaging were manipulated within the boundaries set by contemporary conventions in news reporting and editing. The main pattern in the study findings suggests that the impact of sensationalism on news viewing merely seems to level off at high levels of sensationalism. An interesting question is what we would find if the boundaries in sensationalism are being extended. The present study already 
revealed a small decrease in viewing time among older women. Could we find a more general pattern of decreasing viewing times under conditions of sensationalism that are currently considered extreme? Starting from theories of limited processing capacity (cf. Lang, 2000) and optimal arousal (Csikszentmihalyi, 1992; Donohew et al., 1998) that have been applied in studying audience responses to sensationalism, the answer is definitely affirmative: Extreme levels of sensationalism lead to cognitive overload, overstimulation, or both. In turn, the nongratification of needs for information or entertainment will discourage further viewing.

This question is of more than purely academic interest. A number of studies from the early 2000s have documented a tendency toward more sensational news programs that could well extend into the future (e.g., Djerf-Pierre, 2000; Hendriks Vettehen et al., 2005, 2011; Slattery et al., 2001). Moreover, the rise of fast and mobile communication over the past decade has technically facilitated citizens' participation in the news process. Even as this influence is constrained by organizational and professional regulations, citizens do contribute in the initial stage of the news production, notably by providing eyewitness accounts and video material (cf. Hermida, 2011). As the news coverage of Islamic terrorism shows, these contributions include the most gruesome videos that would not have been available 10 years ago. In all, more extreme levels of sensationalism are likely to be part of the future news environment.

\section{Acknowledgment}

The authors would like to thank Marc Rademaker for his assistance in programming and data collection.

\section{Declaration of Conflicting Interests}

The authors declared no potential conflicts of interest with respect to the research, authorship, and/or publication of this article.

\section{Funding}

The authors received no financial support for the research, authorship, and/or publication of this article.

\section{References}

Ajzen, I., \& Fishbein, M. (2000). Attitudes and the attitude-behavior relation: Reasoned and automatic processes. European Review of Social Psychology, 11, 1-33. doi:10.1080/ 14792779943000116

Arbaoui, B., De Swert, K., \& Van der Brug, W. (2016). Sensationalism in news coverage: A comparative study in 14 television systems. Communication Research. Advance Online Publication. doi:0093650216663364

Bailey, R. L., Fox, J. R., \& Grabe, M. E. (2013). The influence of message and audience characteristics on TV news grazing behavior. Journal of Broadcasting \& Electronic Media, 57, 318-337. doi:10.1080/08838151.2013.816704

Csikszentmihalyi, M. (1992). Flow: The psychology of happiness. London, England: Rider. 
Davis, H., \& McLeod, S. L. (2003). Why humans value sensational news. An evolutionary perspective. Evolution and Human Behavior, 24, 208-216. doi:10.1016/S10905138(03)00012-6

Djerf-Pierre, M. (2000). Squaring the circle: Public service and commercial news on Swedish television 1956-99. Journalism Studies, 1, 239-260. doi:10.1080/14616700050028235

Donohew, L., Lorch, E. P., \& Palmgreen, P. (1998). Applications of a theoretic model of information exposure to health interventions. Human Communication Research, 24, 454-468. doi:10.1111/j.1468-2958.1998.tb00425.x

Grabe, M. E., \& Kamhawi, R. (2006). Hard wired for negative news? Gender differences in processing broadcast news. Communication Research, 33, 346-369. doi:10.1177/ 0093650206291479

Grabe, M. E., Lang, A., \& Zhao, X. (2003). News content and form. Implications for memory and audience evaluations. Communication Research, 30, 387-413. doi:10.1177/ 0093650203253368

Grabe, M. E., Yegiyan, N., \& Kamhawi, R. (2008). Experimental evidence of the knowledge gap: Message arousal, motivation, and time delay. Human Communication Research, 34, 550-571. doi:10.1111/j.1468-2958.2008.00332.x

Grabe, M. E., Zhou, S., \& Barnett, B. (2001). Explicating sensationalism in television news: Content and the bells and whistles of form. Journal of Broadcasting and Electronic Media, 45, 635-655. doi:10.1207/s15506878jobem4504_6

Grabe, M. E., Zhou, S., Lang, A., \& Bolls, P. D. (2000). Packaging television news: The effects of tabloid on information processing and evaluative responses. Journal of Broadcasting \& Electronic Media, 44, 581-598. doi:10.1207/s15506878jobem4404_4

Hendriks Vettehen, P. G. J., Beentjes, J. W. J., Nuijten, C. M., \& Peeters, A. (2011). Arousing news characteristics in Dutch television news 1990-2004: An exploration of competitive strategies. Mass Communication \& Society, 14, 1-20. doi:10.1080/ 15205431003615893

Hendriks Vettehen, P. G. J., Nuijten, C. M., \& Beentjes, J. W. J. (2005). News in an age of competition: Sensationalism in Dutch television news 1995-2001. Journal of Broadcasting \& Electronic Media, 49, 282-295. doi:10.1207/s15506878jobem4903_2

Hendriks Vettehen, P., Nuijten, K., \& Peeters, A. (2008). Explaining effects of sensationalism on liking of television news stories: The role of emotional arousal. Communication Research, 35, 319-338. doi:10.1177/0093650208315960

Hendriks Vettehen, P. G. J., Zhou, S., Kleemans, M., d'Haenens, L., \& Lin, T. T. (2012). Competitive pressure and arousing television news: A cross-cultural study. Asian Journal of Communication, 22, 179-196. doi:10.1080/01292986.2011.642394

Hermida, A. (2011). Mechanisms of participation. In J. B. Singer, A. Hermida, D. Domingo, A. Heinonen, S. Paulussen, T. Quandt, Z. Reich, \& M. Vujnovic (Eds.), Participatory journalism: Guarding open gates at online newspapers (pp. 13-33). Oxford, England: Wiley-Blackwell. doi:10.1002/9781444340747.ch2

Hjarvard, S. (2000). Proximity: The name of the ratings game. Nordicom Review, 21, 63-81. Hvitfelt, H. (1994). The commercialization of the evening news: Changes in narrative technique in Swedish TV News. Nordicom Review, 15, 33-41. 
Kamhawi, R., \& Grabe, M. E. (2008). Engaging the female audience: An evolutionary psychology perspective on gendered responses to news valence frames. Journal of Broadcasting \& Electronic Media, 52, 33-51. doi:10.1080/08838150701820783

Kleemans, M., Hendriks Vettehen, P. G. J., Beentjes, J. W. J., \& Eisinga, R. (2012). The influence of age and gender on preferences for negative content and tabloid packaging in television news stories. Communication Research, 5, 679-697. doi:10.1177/ 0093650211414559

Kleemans, M., Hendriks Vettehen, P. G. J., Eisinga, R., \& Beentjes, J. W. J. (2014). Enjoyment of arousing television news: The role of age and sensation seeking. Communications, The European Journal of Communication Research, 39, 89-99. doi:10.1515/commun-20140006

Lang, A. (2000). The limited capacity model of mediated message processing. Journal of Communication, 50, 46-70. doi:10.1111/j.1460-2466.2000.tb02833.x

Lang, A., Newhagen, J., \& Reeves, B. (1996). Negative video as structure: Emotion, attention, capacity, and memory. Journal of Broadcasting \& Electronic Media, 40, 460-477. doi:10.1080/08838159609364369

Obama, B. (2012). Remarks by the President at Barnard College Commencement Ceremony. Retrieved from https://www.whitehouse.gov/the-press-office/2012/05/14/remarks-presi dent-barnard-college-commencement-ceremony

Palmgreen, P., Wenner, L. A., \& Rayburn, J. D. (1980). Relations between gratifications sought and obtained: A study of television news. Communication Research, 7, 161-192. doi:10. $1177 / 009365028000700202$

Prior, M. (2003). Any good news in soft news? The impact of soft news preference on political knowledge. Political Communication, 20, 149-171. doi:10.1080/10584600390211172

Rubin, A. M., Perse, E. M., \& Powell, R. A. (1985). Loneliness, parasocial interaction, and local television news viewing. Human Communication Research, 12, 155-180. doi:10.1111/j. 1468-2958.1985.tb00071.x

Shoemaker, P. J. (1996). Hardwired for news: Using biological and cultural evolution to explain the surveillance function. Journal of Communication, 46, 32-47. doi:10.1111/j.1460-2466. 1996.tb01487.x

Slattery, K. L., Doremus, M., \& Marcus, L. (2001). Shifts in public affairs reporting on the network evening news: A move toward the sensational. Journal of Broadcasting \& Electronic Media, 45, 290-302. doi:10.1207/s15506878jobem4502_6

Soroka, S., \& McAdams, S. (2015). News, politics, and negativity. Political Communication, 32, 1-22. doi:10.1080/10584609.2014.881942

\section{Author Biographies}

Paul Hendriks Vettehen, $\mathrm{PhD}$, is an assistant professor at the Behavioural Science Institute, Radboud University, PO Box 9104, 6500 HE Nijmegen, the Netherlands.

Mariska Kleemans, $\mathrm{PhD}$, is an assistant professor at the Behavioural Science Institute, Radboud University, PO Box 9104, 6500 HE Nijmegen, the Netherlands. 